\title{
Von Willebrand disease in pregnancy: a case report
}

\section{Rashmi A. G., Riya Kumar*, Dayamayi A. S., Spandana Nallipilli}

Department of Obstetrics and Gynecology, Rajarajeswari Medical College and Hospital, Bangalore, Karnataka, India

Received: 16 October 2021

Revised: 09 November 2021

Accepted: 10 November 2021

\author{
*Correspondence: \\ Dr. Riya Kumar, \\ E-mail: riya.kumar94@gmail.com
}

Copyright: ( $)$ the author(s), publisher and licensee Medip Academy. This is an open-access article distributed under the terms of the Creative Commons Attribution Non-Commercial License, which permits unrestricted non-commercial use, distribution, and reproduction in any medium, provided the original work is properly cited.

\begin{abstract}
Von Willebrand disease (VWD) is a hereditary bleeding disorder that can be severe and potentially life-threatening, particularly in pregnant women during labor and subsequently during early puerperium. There is no optimal treatment or management for this disorder. Hence, all efforts aim at early diagnosis and the focus is mainly on minimising and controlling blood loss. We described the case of a woman in the post-partum period with severe VWD, admitted in the obstetrics and gynaecology ward at Rajarajeswari Medical College and Hospital, Bangalore. Prompt diagnosis, initiation of pre-partum and intra-partum Von Willebrand factor (VWF)/clotting factor replacement therapy, vigilant post-partum monitoring of blood loss and systematic follow up will help expedite recovery and prevent adverse outcomes.
\end{abstract}

Keywords: Von Willebrand disease, Pregnancy, Postpartum hemorrhage, Bleeding disorder, Blood products

\section{INTRODUCTION}

Von Willebrand disease (VWD) is the most common hereditary blood-clotting disorder. ${ }^{2}$

Von Willebrand factor (VWF), is a multimeric protein that is essential for platelet adhesion and serves as a carrier protein for factor VIII. ${ }^{3}$ The quantitative or qualitative deficiency of this factor leads to VWD, which can be of three types, i.e.; hereditary, acquired, and pseudo or platelet type. ${ }^{4,5}$

The International Society on Thrombosis and Haemostasis last published their official recommendations concerning VWD classification in $2006 .{ }^{6}$ In this classification, VWD is considered as either a quantitative (type 1 and 3 ) or qualitative (type 2) trait. The 3 types present with varying degrees of bleeding, usually in the form of easy bruising, spontaneous bleeding manifestations like nosebleeds, bleeding gums, heavy menstrual periods and excessive blood loss during childbirth. ${ }^{7}$ The prevalence of VWD is about 1 in 100 individuals. ${ }^{8}$ Majority of these cases do not have symptoms, owing to which the prevalence of clinically significant cases is 1 per $10,000{ }^{8}$ Considering most forms are silent and asymptomatic, they are identified more often in women, whose bleeding tendencies become obvious during menstrual cycles. Hence, the prevalence in women is approximately twice that documented in men. ${ }^{9}$

Pregnancy in women with VWD poses a special challenge that warrants brief clinical dialogue. Bleeding complications during pregnancy are more frequent when levels of the von Willebrand ristocetin cofactor assay and factor VIII levels are $<50 \mathrm{IU} / \mathrm{dl}$ and in those who do not receive adequate prophylactic therapy. ${ }^{10}$ The risk persists for several weeks, with reports of haemorrhage up to 3-5 weeks postpartum. ${ }^{11}$

VWD may also exacerbate bleeding due to other obstetric causes, such as uterine atony, episiotomy, intramuscular injections or a traumatic delivery. Owing to the large proportion of undetected cases and difficulty in diagnosis, VWD continues to be an elusive and ambiguous disorder. 
In our report, we review the case of a woman with severe VWD, who presenteded with continuous bleeding per vaginum in the post-partum period.

Through this case report, we wish to bring to the foreground the importance of early detection and prompt management of this disease.

\section{CASE REPORT}

We report a case of a 30 year old lady, P1L1, referred to us on post-operative day 19 of emergency caesarean section, done in view of failed labor induction. Patient presented with continuous and heavy bleeding per vaginum following caesarean section and pain at the incision site. She gave history of using 5-6 pads per day and described the bleeding as thin and watery.

Patient also gave history of easy bruising, prolonged bleeding from wounds and skin abrasions, spontaneous gum bleeds and menorrhagia since childhood. Similar history of bruising and excessive bleeding was furnished in her brother. Patient's mother gave negative history of bleeding tendencies and reported uneventful obstetric and menstrual history. Investigations done at the primary hospital showed prolonged bleeding and clotting times along with raised Activated partial thromboplastin time (APTT) value of $69.65 \mathrm{sec}$.

On admission at our hospital, patient had tachycardia but was otherwise hemodynamically stable. Local examination revealed minimal ooze and significant induration along the suture line. Lab investigations showed isolated raise in APTT of $57.9 \mathrm{sec}$, haemoglobin of $10.6 \mathrm{~g} \%$, platelet count of 5.3 lakhs $/ \mu 1$ and peripheral smear showing giant platelets and mild degree of anisopoikilocytosis.

Abdominopelvic scan was done and showed a hypoechoic collection of 10-12 $\mathrm{cc}$ anterior to the uterus tracking upto to the anterior uterine wall and a hypoechoic collection in the intramuscular plane which was suggestive of a hematoma. Patient was treated with vitamin $\mathrm{K}$ injection, oral ethamsylate, intravenous trenaxemic acid and one pint of FFP, which alleviated the bleeding to about 2 pads per day.

No surgical wound revision or substitutive therapy with VWF concentrate was necessary. On the basis of the clinical presentation and preliminary lab reports, a tentative diagnosis of VWD was made. Patient was sent to a haematology unit for further work up and coagulation factor assaying. The investigations mentioned in Table 1 were done. Patient was diagnosed with severe VWD and was advised cryoprecipitate or VWF concentrate in the event of acute or excessive bleeding.

She was continued on oral ethamsylate and trenaxemic acid on discharge, as bleeding had significantly reduced. No further transfusions were done. 2 weeks following discharge, patient presented back to our OPD with repeat episode of bleeding per vaginum since 3 to 4 days, changing 5 to 6 pads per day. On admission, patient appeared pale but was otherwise hemodynamically stable. Investigations revealed severe anaemia of $5 \mathrm{~g} \%$ and APTT of $69.4 \mathrm{sec}$. Platelet count had decreased as compared to previous reports and was $1.261 / \mu 1.2$ units of packed cells, 5 units of cryoprecipitate and 1 unit of fresh frozen plasma were transfused, following which the bleeding stopped. Patient was closely monitored for one week and discharged from the hospital.

She continued to have intermittent episodes of bleeding per vaginum over the course of the next 3 weeks, albeit considerably lesser in amount. She was treated conservatively with trenaxemic acid. Patient and family members were counseled regarding the need for testing of siblings and the risk of severe bleeding in the event of future pregnancies. Husband was counseled to undergo a vasectomy.

Table 1: Baseline investigations.

\begin{tabular}{|lll|}
\hline Parameters & Test result & Reference range \\
\hline PT (sec) & 12.2 & $10.2-14.2$ \\
\hline APTT (sec) & 62.30 & $27-36$ \\
\hline $\begin{array}{l}\text { Bleeding } \\
\text { time (min) }\end{array}$ & 12 & 1 to 9 \\
\hline Haemoglobin (g/dl) & 9.4 & $12-16$ \\
\hline $\begin{array}{l}\text { Platelet } \\
\text { count (lakh/ } \mathbf{\mu l})\end{array}$ & 4.16 & $1.5-4$ \\
\hline Peripheral smear & $\begin{array}{l}\text { Platelet } \\
\text { aggregates } \\
\text { seen }\end{array}$ & - \\
\hline
\end{tabular}

Table 2: Mixing studies for PT/APTT.

\begin{tabular}{|lll|}
\hline Parameters & Test result & Reference range \\
\hline $\begin{array}{l}\text { APTT 0.5 } \\
\text { patient+0.5 control }\end{array}$ & $33.8 \mathrm{sec}$ & \\
\hline Factor VIII assay & 3.1 & $50-150 \mathrm{IU} / \mathrm{dl}$ \\
\hline $\begin{array}{l}\text { Test for factor XIII } \\
\text { (urea solubility } \\
\text { test) }\end{array}$ & Negative & \\
\hline VWF antigen assay & $<1.0$ & $50-150 \mathrm{IU} / \mathrm{dl}$ \\
\hline
\end{tabular}



Figure 1: Pedigree chart. 


\section{DISCUSSION}

VWD is the most common inherited bleeding disorder that occurs due to a defect in VWF, which is a glycoprotein crucial for platelet adhesion to the vascular endothelium following injury. ${ }^{12}$

VWF is a complex multimeric protein with two roles: it forms an adhesive bridge between the circulating platelets and sites of vascular damage and it also binds to factor VIII, providing stability and maintaining the integrity of the clotting cascade. ${ }^{12}$

VWF binds to platelets via specific receptors, most notably glycoprotein Ib (GPIb), and GPIIb/IIIa. It also attaches to sub-endothelial matrix components, mainly collagen and in this way facilitates the anchoring of platelets to damaged endothelium. ${ }^{12}$

Patients with VWD may present with severe mucosal bleeds (owing to platelet dysfunction) and prolonged bleeding (owing to factor VIII deficiency). ${ }^{13}$ The autosomal inheritance pattern means equal predilection of disease in both sexes. However, there is a higher incidence of symptomatic and apparent disease in women because of the haemostatic challenges faced during menstruation and childbirth. ${ }^{14}$

A history of recurrent and prolonged bleeding, easy bruising and any other forms of mucocutaneous bleeds should prompt us in the direction of VWD. In such cases, an ideal panel of tests should include APTT, PT, bleeding time, factor VIII: C Ristocetin cofactor and VWF antigen assay. There is a progressive increase in FVIII and VWF levels during normal pregnancy. ${ }^{15}$ Most studies suggest that this increase begins during the second trimester, reaching peak levels at term, followed by a return to baseline during the puerperal period. ${ }^{16}$

The same increase in FVIII and VWF is also seen in women with VWD, which may contribute to the improvement in minor bleeding manifestations, during pregnancy. ${ }^{17}$ The haemostatic response in pregnancy depends on the type as well as the severity of disease most women with type 1 VWD or less severe forms of the disease have a progressive increase in FVIII and VWF levels into the normal non-pregnant range, which may mask the diagnosis during pregnancy. ${ }^{18}$ However, levels may remain low in severe cases. ${ }^{18}$

Very few studies have measured FVIII and VWF levels in women with VWD during the postpartum period. Most reports go to show that levels may fall precipitously after delivery. ${ }^{19}$ Multiple studies suggest that women with VWD are at peril for severe postpartum haemorrhage as well. In a study done by Ramsahoye et al, primary postpartum haemorrhage complicated 16-29\% of pregnancies, while secondary postpartum haemorrhage (after the first 24h) complicated 20-29\% deliveries, necessitating transfusion of blood and blood products. ${ }^{20}$
In a substantial number of cases, the diagnosis of VWD was unknown prior to presentation of postpartum haemorrhage. ${ }^{21}$ In the largest study done by Kadir et al, there was no immediate postpartum haemorrhage in women who received prophylactic therapy with VWF concentrates. $^{22}$ However, intermittent or delayed postpartum bleeding may persist for prolonged periods, despite prophylactic therapy. ${ }^{22}$

Frequent monitoring and continued treatment is recommended for at least 2 weeks after delivery. The treatment of choice in mild forms is the synthetic agent desmopressin. ${ }^{20}$ In patients with severe type 1, 2 and 3 disease or in people who do not respond to desmopressin, the appropriate treatment is factor VIII concentrate that is rich in VWF. ${ }^{20}$ In our case, the isolated increase in APTT prompted further investigation and pointed us in the direction of VWD.

In a country like India, financial inadequacies and lack of awareness hampers requisite and prompt diagnosis and management. Further, limited resources and nonavailability of clotting factor concentrates in many hospital setups hinders optimal treatment.

With these considerations in mind, our patient was primarily managed with cryoprecipitate pools and trenaxemic acid.

Desmopressin was not administered owing to two factors: (1) the severity of disease, which goes in favour of unresponsiveness to the drug; and (2) the risk of desmopressin induced seizures in the post-partum period. Siblings were counselled regarding the likelihood of having VWD and the need for testing of clotting factors and coagulation profiling in them. Family planning counselling was also instituted and the husband was advised to undergo a vasectomy. Measures that could have been adopted in our case to expedite recovery: (1) transfusion of cryoprecipitate or VWF concentrates prior to delivery/surgery at the primary care hospital; (2) intraoperative transfusion of cryoprecipitate or VWF concentrate; and (3) typing of disease.

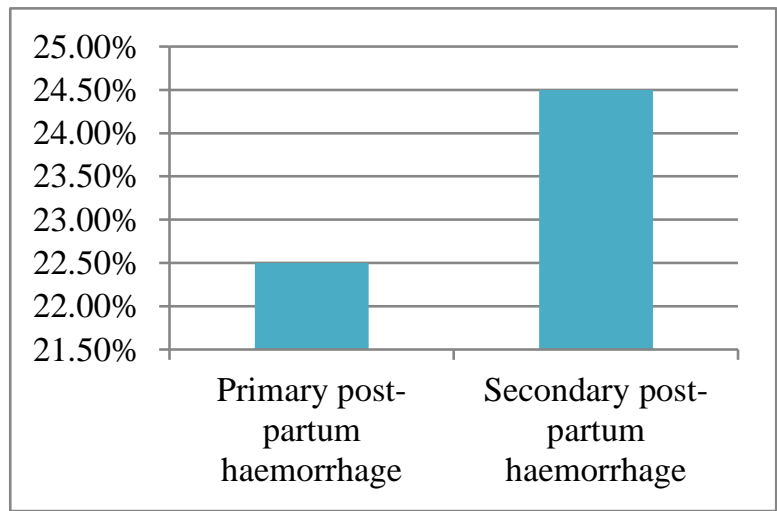

Figure 2: Incidence of post-partum haemorrhage in VWD. ${ }^{20}$ 


\section{CONCLUSION}

The diagnosis and management of VWD poses a challenging and arduous clinical task, which is particularly overwhelming in an obstetric scenario. Through this case report, we wish to emphasise the importance of prompt diagnosis, initiation of pre-partum and intra-partum VWF/clotting factor replacement therapy, vigilant postpartum monitoring of blood loss and systematic follow up in all cases of VWD, as these measures will help in optimum recovery and prevent adverse outcomes.

Funding: No funding sources

Conflict of interest: None declared

Ethical approval: Not required

\section{REFERENCES}

1. Inocêncio $\mathrm{G}$, Braga $\mathrm{A}$, Azevedo $\mathrm{S}$, Buchner $\mathrm{G}$. Management of von Willebrand disease type 3 during pregnancy - 2 cases reports. Eur Rev Med Pharmacol Sci. 2013;17(21):2857-9.

2. National Library of Medicine. Von Willebrand disease: MedlinePlus Medical Encyclopedia, 2012. Available at: https://medlineplus.gov/genetics/condition/vonwilleb rand-disease/. Accessed on 07 October 2021.

3. Kujovich JL. von Willebrand disease and pregnancy. J Thromb Haemost. 2005;3(2):246-53.

4. Nichols WL, Rick ME, Ortel TL, Montgomery RR, Sadler JE, Yawn BP, et al. Clinical and laboratory diagnosis of von Willebrand disease: a synopsis of the 2008 NHLBI/NIH guidelines. Am J Hematol. 2009;84(6):366-70.

5. Goodeve A, James P. von Willebrand Disease. In: Adam MP, Ardinger HH, Pagon RA, Wallace SE, Bean LJH, Mirzaa G, et al, eds. GeneReviews ${ }^{\circledR}$. Seattle, WA: University of Washington, Seattle; 2009: 1993-2021.

6. Sadler JE, Budde U, Eikenboom JC, Favaloro EJ, Hill FG, Holmberg L, et al. Update on the pathophysiology and classification of von Willebrand disease: a report of the Subcommittee on von Willebrand Factor. J Thromb Haemost. 2006;4(10):2103-14.

7. National Haemophilia Foundation. National Haemophilia Foundation for all bleeding disorders, 2021. Available at: https://www.hemophilia.org/. Accessed on 07 October 2021.

8. Molecular basis of von Willebrand disease and its clinical implications. Haematologica. 2004;89(9):1036.

9. Lilicarp D, Jams P. Von Willebrand disease: an introduction for the primary care physician. Canada: World Federation of Hemophilia; 2009.
10. Pacheco LD, Costantine MM, Saade GR, Mucowski S, Hankins GD, Sciscione AC. von Willebrand disease and pregnancy: a practical approach for the diagnosis and treatment. Am J Obstet Gynecol. 2010;203(3):194-200.

11. Conti M, Mari D, Conti E, Muggiasca ML, Mannucci PM. Pregnancy in women with different types of von Willebrand disease. Obstet Gynecol. 1986;68(2):2825.

12. Echahdi H, Hasbaoui B, Khorassani M, Agadr A, Khattab M. Von Willebrand's disease: case report and review of literature. Pan Afr Med J. 2017;27:147.

13. Kujovich JL. von Willebrand disease and pregnancy. J Thromb Haemost. 2005;3(2):246-53.

14. Sadler JE, Mannucci PM, Berntorp E, Bochkov N, Boulyjenkov V, Ginsburg D, et al. Impact, diagnosis and treatment of von Willebrand disease. Thromb Haemost. 2000;84(2):160-74.

15. Sié P, Caron C, Azam J, Goudemand J, Grandjean H, Boneu B, et al. Reassessment of von Willebrand factor (VWF), VWF propeptide, factor VIII:C and plasminogen activator inhibitors 1 and 2 during normal pregnancy. Br J Haematol. 2003;121(6):897903.

16. Clark P, Brennand J, Conkie JA, McCall F, Greer IA, Walker ID. Activated protein C sensitivity, protein C, protein $\mathrm{S}$ and coagulation in normal pregnancy. Thromb Haemost. 1998;79(6):1166-70.

17. Kadir RA, Lee CA, Sabin CA, Pollard D, Economides DL. Pregnancy in women with von Willebrand's disease or factor XI deficiency. Br J Obstet Gynaecol. 1998;105(3):314-21.

18. Chediak JR, Alban GM, Maxey B. von Willebrand's disease and pregnancy: management during delivery and outcome of offspring. Am J Obstet Gynecol. 1986;155(3):618-24.

19. Hanna W, McCarroll D, McDonald T, Painter P, Tuller J, Chen J, Lange R. Variant von Willebrand's disease and pregnancy. Blood. 1981;58(5):873-9.

20. Ramsahoye BH, Davies SV, Dasani H, Pearson JF. Obstetric management in von Willebrand's disease: a report of 24 pregnancies and a reivesw of the literature. Haemophilia. 1995;1(2):140-4.

21. Ragni MV, Bontempo FA, Hassett AC. von Willebrand disease and bleeding in women. Haemophilia. 1999;5(5):313-7.

22. Kadir RA, Lee CA, Sabin CA, Pollard D, Economides DL. Pregnancy in women with von Willebrand's disease or factor XI deficiency. Br J Obstet Gynaecol. 1998;105(3):314-21.

Cite this article as: Rashmi AG, Kumar R, Dayamayi AS, Nallipilli S. Von Willebrand disease in pregnancy: a case report. Int J Reprod Contracept Obstet Gynecol 2021;10:4602-5. 